According to the space allowance proposed by PETHERICK (1983) from a weight of $60 \mathrm{~kg}$ all animals could not rest on their sternum at the same time : $0.34 \mathrm{~m}^{2} / \mathrm{pig}$, or fully recumbent : $0.68 \mathrm{~m}^{2} / \mathrm{pig}$ from a weight of $60-70 \mathrm{~kg}$, or no space restriction : $1.01 \mathrm{~m}^{2} / \mathrm{pig}$. Production performance was deteriorated in pigs allowed only $0.34 \mathrm{~m}^{2} / \mathrm{pig}$ perceptible from 10 weeks following the beginning of the experiment $(70-80 \mathrm{~kg})$ and until slaughter i.e. 5 to 16 p. 100 : daily gain; 7 to 14 p. 100 : feed efficiency.

Behavioural observations in spontaneous situation and space restriction of $0.34 \mathrm{~m} \% / \mathrm{pig}$ showed a larger individual time spent at the trough in relation with a monopolization by four animals. During a 24-h cycle, resting behaviour was expressed more in sternum position when live weight reached $60 \mathrm{~kg}$. In addition, social and playing behaviour were a little reduced. No difference was observed between the two treatments : $0.68 \mathrm{~m}^{2} / \mathrm{pig}$ and $1.01 \mathrm{~m}^{2} /$ pig. Animals did not exhibit an abnormal behaviour (tail biting, belly nosing) in any of the three treatments.

In conclusion, a severe restriction did not increase the aggressivity, but induced a "social avoidance» between animals. Even though adaptative capacities of the growing pig were observed, differences between treatment tended to show an alteration of the behaviour of animals from 8 weeks after the beginning of the experiment $(50-60 \mathrm{~kg}$ ), whereas no trouble appeared in weight performance. Behaviour parameters such as feeding, resting, spatial behaviour and social relationships appeared to be more sensitive and more early indicators of disturbance than growth performance.

\title{
Pig house exhibition and testing centre in Trevarez (France)
}

\author{
J. CALLAREC \\ Etablissement Départemental de l'Elevage du Finistère, \\ 3, allée Sully, B.P. 504, 29109 Quimper Cedex
}

The first characteristic of the pighouse exhibition and testing centre in Trevarez is to be designed by and for people responsible for popularization, E.D.E. (*) and chambers of Agriculture of Brittany with the support of the I.T.P. $\left(^{*}\right)$ of Rennes. It is not a centre of research on pig housing, but an exhibition centre of the different models of piggeries designed and managed according to the recently defined pig environmental requirements, especially temperature.

The following models are exhibited :

- 11 models of fattening piggeries - for 810 individuals;

- 3 models of boar-pregnant sows houses - for 24 sows and 3 boars;

- 3 farrowing houses - for 9 individuals ;

- 3 models of post-weaning houses - for 180 individuals.

Moreover, equipment for inner arrangement, ventilation and heating are exhibited and building techniques are displayed.

Performances are measured in each piggery. It may be concluded after three years of operation that fattening results are very similar from one model to another.

(*) E.D.E. : Etablissement Départemental de l'Elevage du Finistère.

(*) I.T.P. : Institut Technique du Porc. 